\title{
EtniCidades: os 400 anos de Belém e a presença indígena
}

\section{EthniCities: the 400th anniversary of Belém and the indigenous presence}

\begin{abstract}
Ivânia dos Santos NEVES
Universidade Federal do Pará (UFPA)

Resumo: Em 12 de janeiro de 2016, Belém completará, oficialmente, 400 anos de fundação. A comemoração deste aniversário representa uma homenagem ao processo de colonização europeia na região. A movimentação em torno deste acontecimento começou a ser planejada por diferentes setores da sociedade belenense, com bastante antecedência. Diferentes sujeitos construíram diferentes discursos para falar sobre esta região. Este processo de 400 anos não foi pacífico, nem igualitário, pelo contrário, foi marcado pelo silenciamento de memórias, pela imposição da língua portuguesa, pela arquitetura colonial. A história da cidade, no entanto, é plural, ela é constituída por resistência e negociações culturais. Se por um lado a prefeitura e as grandes corporações de comunicação defendem uma memória europeia para a região, de outro, os grafites e pichações e a intensa movimentação no Facebook e Youtube exibem a pluralidade étnica que a cidade comunica. Neste artigo, analiso como, apesar do sistema colonial e de suas atualizações, a memória indígena está presente nas tensões discursivas que envolvem as comemorações.
\end{abstract}

Palavras-Chave: Sistema colonial, acontecimento, dispositivo, memória indígena.

\begin{abstract}
On January 12, 2016, Belém complete, officially, 400 years of foundation. This is thus a tribute to the European colonization process in the region. Moving around this event began to be planned by different sectors of local society, well in advance. Different subjects have built different discourses to talk about this region. This process 400 years was not peaceful or egalitarian, but marked by silencing memories, by the imposition of Portuguese, the colonial architecture. The city's history, however, is plural, is constituted with resistance and cultural negotiations. If on one hand City Hall and the large media corporations defend a European memory for the region, on the other hand, graffiti and intense movement on Facebook and Youtube show the ethnic plurality which the city communicates. In this article, I analyze how despite of the colonial system and its updates, the indigenous memory is present in the discursive tensions surrounding the celebrations.
\end{abstract}

Keywords: Colonial system, event, device, indigenous memory

\section{Introdução}

Que cidade é essa onde a paisagem que a comunica, a esconde como
espaço de vida feito de convergências e divergências, mas sempre
prontas a serem revistas e reescritas?
Que cidade é essa, onde a imagem que a registra, pode esconder a
paisagem que nos poderia levar a redescobri-la? Será que é próprio da
paisagem registrar e esconder ao mesmo tempo ou é sua função
comunicar, ao mostrar a incompletude da cidade contemporânea e
global?
Lucrécia Ferrara

Na entrada de Belém, no recém-inaugurado Complexo viário do Entroncamento, única entrada rodoviária da cidade até 2015, uma série de pichações e grafites, aos poucos, estão ocupando os espaços cinzas das paredes que contornam as duas rodovias e os viadutos que formam o complexo. A imagem a seguir é um recorte deste espaço, 
onde aparecem algumas pichações: o enunciado verbal "Nós é índio", ao lado de um grafismo indígena e de outro enunciado, menos compreensível ao público em geral, as siglas de um coletivo de pichadores.

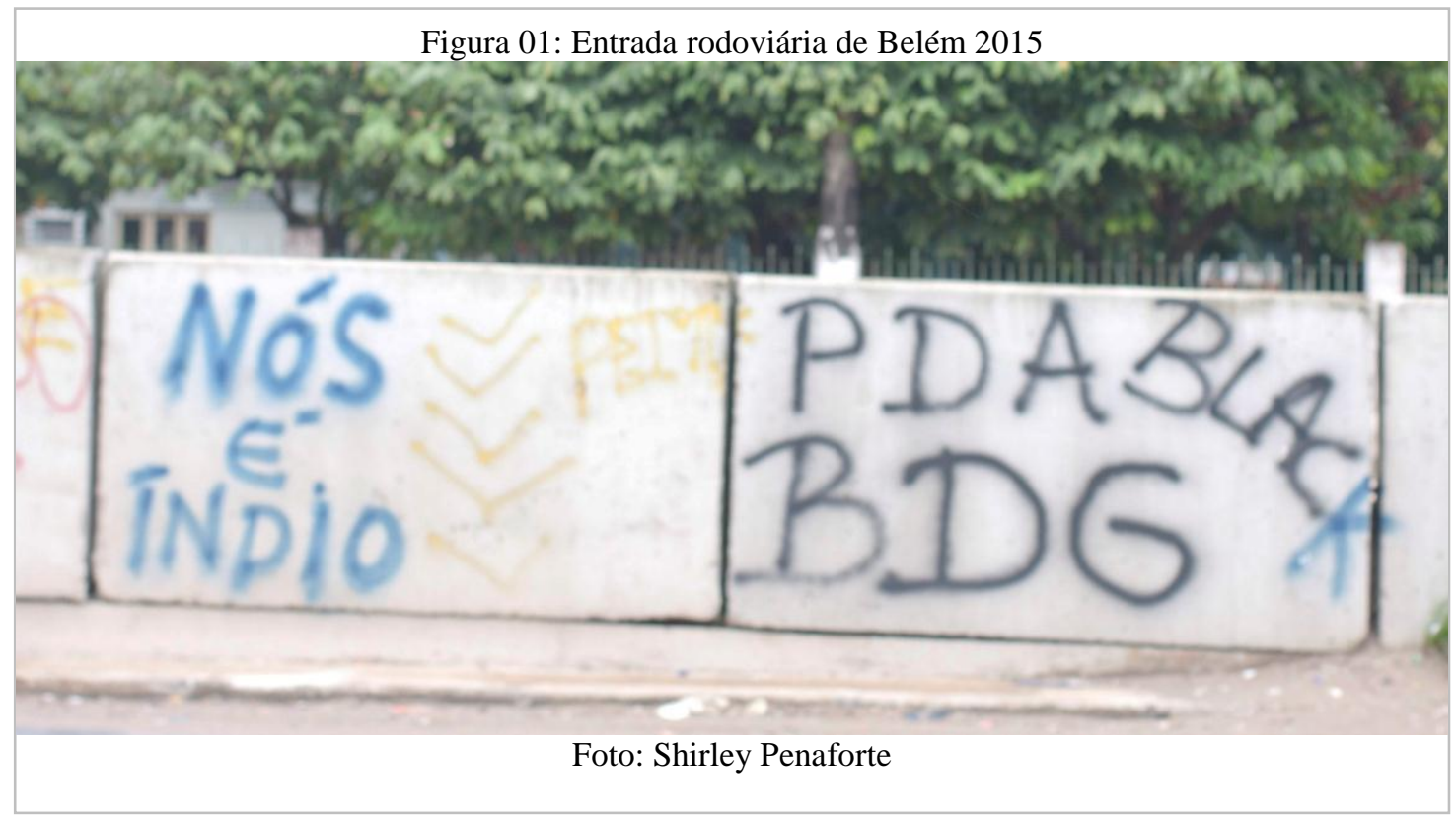

Às vésperas do aniversário do quarto centenário, a presença de grafites e de pichações envolvendo a pluralidade étnica da cidade, que aqui vou tomar como etnicidade, multiplicou-se nos mais diferentes espaços da cidade. Chama bastante atenção a presença destes enunciados espalhados na caótica urbanidade de Belém. Simultânea a esta movimentação, a Prefeitura e o Governo do Estado organizam uma grande comemoração de aniversário e anunciam, inspirados no modelo de urbanidade parisiense, a "Cidade Luz da Amazônia". Nas redes sociais, os três últimos aniversários também mereceram muita atenção dos moradores e há uma série de páginas criadas no Facebook e vídeos amadores postados no Youtube que contestam a ficcionalidade da cidade iluminada e europeia.

Estas contraditórias manifestações visibilizam uma das mais pulsantes tensões discursivas presente na construção das cidades latino-americanas. E se o aniversário toma como referência a data inicial da colonização lusitana, os 400 anos de história da cidade já complexificaram bastante o dualismo colonizador-colonizado. Podemos então pensar numa pluralidade étnica que envolve a priori povos indígenas, portugueses e africanos trazidos para cá como escravos, mas hoje, a presença de japoneses, sírios, haitianos, italianos, entre outros, somada aos usos sistemáticos das redes sociais, que dilui as fronteiras transnacionais e este dualismo resulta em uma simplificação.

Em 12 de janeiro de 2016, Belém, capital do estado do Pará, localizada na Amazônia brasileira, completará, oficialmente, 400 anos de fundação. A comemoração desta data, proposta por alguns setores da sociedade local representa, sem dúvida, uma homenagem ao processo de colonização europeia na região. Diferentes sujeitos construíram diferentes discursos para falar sobre a cidade e não foi um processo pacífico, nem igualitário, pelo contrário, foi marcado pelo silenciamento das memórias indígenas e africanas, pela imposição da língua portuguesa e da arquitetura colonial. Não haveria, portanto, um paradoxo entre esta comemoração agenciada pelo poder público e a pluralidade étnica da cidade? 
Neste artigo, tratarei mais especificamente das memórias indígenas que emergem em meio a este grande acontecimento discursivo, agenciado por diferentes sujeitos e seus interesses ora convergentes, ora conflitantes. Entendo, a partir das formulações de Foucault (2005), o sistema colonial como um grande dispositivo, sempre atualizado pelas emergências da história.

Desde o início sistemático da colonização do continente americano, a cosmologia eurocêntrica passou a delinear uma ordem hegemônica, que determina inclusive as línguas oficiais da ciência ocidental, que são todas europeias. Este processo contínuo e difuso foi sempre marcado pela resistência a esta ordem e entre outros efeitos, produziu nas sociedades latino-americanas uma condição de "estar ou sentir-se entre":

A diferença colonial cria condições para situações dialógicas, nas quais se encena, do ponto de vista subalterno uma enunciação fraturada como reação ao discurso e à perspectiva hegemônica. Assim, o pensamento liminar é mais do que uma enunciação híbrida. É uma enunciação fraturada em situações dialógicas com a cosmologia territorial e hegemônica. (MIGNOLO, 2003, p.11)

Pretendo analisar como as condições de possibilidades deste momento histórico evidenciam as memórias indígenas, a partir desta perspectiva liminar, em meio à pluralidade étnica da cidade. Desde o início do século XIX, não existem mais sociedades indígenas organizadas na área metropolitana de Belém, mas não se pode negar a forte herança destas sociedades no cotidiano da cidade.

No Grão Pará, a população de fala portuguesa que por lá se instalou era extremamente reduzida: cerca de 150 indivíduos, na maioria soldados que chegaram em 1616 com Francisco Caldeira Castelo Branco. Um século depois, os portugueses na Amazônia totalizariam mil pessoas, enquanto os diferentes povos indígenas ainda continuavam a ser majoritários. Em 1720, os índios escravos e livres, integrados ao sistema colonial, eram aproximadamente 75 mil, excluídos aqui aqueles que permaneciam autônomos. (BESSA FREIRE, 2004 p.54)

Uma parte da sociedade local, neste momento, reivindica nos muros e nas redes sociais o reconhecimento da descendência indígena e da descendência africana. Não se trata aqui de analisar o aniversário do quarto centenário como um acontecimento isolado, mas sim de realizar uma análise que procure compreender os processos históricos e culturais que fazem de Belém uma cidade latino-americana com todas as suas contradições ${ }^{1}$.

As cidades não são apenas um limite geográfico, ou uma organização política definida, mas sim complexos processos históricos e culturais sempre inconclusos. Neste sentido, também entendo suas paisagens contemporâneas como significativos enunciados, um meio de produção de sentidos, portanto passivas às relações de poder. Nas formulações de Lucrécia Ferrara (2008, p.42):

\footnotetext{
${ }^{1}$ As pesquisas que deram ensejo a este artigo são desenvolvidas no âmbito do projeto "400 anos depois: experiências nas paisagens de Belém", aprovado pelo Edital de Ciências Humanas do CNPq, para o biênio 2015/2016.
} 
Os índices materiais e formais constroem as cidades e permitem que sua imagem constitua a mídia mais eloquente e eficaz. Apreender essa mídia, considerando seus suportes construtivos, nos leva a constatar que, às características urbanísticas e funcionais de uma cidade, alia-se a dimensão comunicativa que faz com que a cidade surja sempre e, sobretudo nos dias atuais, de um lado, como eficiente mídia a sustentar as ambições e planos globais e, de outro, nos surpreenda pelas imponderáveis e inesperadas manifestações de vida que vão muito além da simples intenção midiática.

Para os diferentes sujeitos que moram em Belém, atualmente, a multifacetada paisagem da cidade é um construto midiático, mercadológico, mas é também o espaço onde constroem seus afetos e escrevem o seu cotidiano. Os processos de mediação agenciados por estes moradores estão produzindo dinâmicas singulares, baseadas na experiência muitas vezes imprevisível e contraditória com a cidade.

\section{O sistema colonial/colonialidade como dispositivo e a construção das cidades}

A fundação das cidades paraenses aconteceu, em linhas gerais, a partir de dois diferentes momentos históricos. Os primeiros municípios, como Belém, Vigia, Cametá e Bragança, ainda no período colonial, a partir do século XVII, nasceram às margens dos rios da bacia amazônica e tinham como principal objetivo garantir a posse portuguesa desta região, bastante ameaçada pela presença francesa. Mais recentemente, já no século XX, no rastro da construção de grandes rodovias, voltadas à integração nacional da Amazônia, e dos grandes projetos de exploração mineral e agropecuária, pequenas cidades surgiram no interior do estado, como é o caso de Paragominas, Ulianópolis, Goianésia.

Como aconteceu com a grande maioria das cidades latino-americanas, Belém foi constituída a partir de uma pluralidade étnica, que começou com o genocídio de muitas sociedades indígenas. Lamentavelmente e "naturalmente", a história, desde 1612, é contada pelos grupos que estiveram no poder. Do início da colonização europeia até os nossos dias, a história e a produção do conhecimento oficial viveu e vive sob a ditadura da palavra escrita ocidental, europeia, branca e suas poderosas verdades. Em meio a estes processos, cria-se uma ficção sobre os usos das línguas europeias, que se impõem como as únicas referências linguísticas possíveis.

Durante os longos séculos de colonização, neste continente, a construção das cidades representou uma das mais poderosas estratégias disciplinadoras das práticas culturais dos indígenas e dos povos africanos. Elas representaram o mais preciso ponto de inserção na realidade desta configuração cultural e se consolidaram como um modelo urbano de duração secular, ainda muito presentes na América Latina: a cidade barroca. (RAMA, 1985). A palavra europeia prescindia de novos espaços para a encenação de seus rituais. A arquitetura colonial com suas igrejas e suas escolas, muitas vezes construídas por sobre lugares indígenas sagrados, representa, hoje, em cidades como São Luís e Ouro Preto patrimônio cultural da humanidade.

Não houve um único sujeito responsável por conduzir este grande dispositivo de poder que é o sistema colonial, nem ele pode ser compreendido como um processo heterogêneo, sem atualizações. A partir do século XV, os Estados europeus, com seus exércitos e seus anseios de se tornarem impérios, as grandes empresas que começavam a surgir e desejavam abrir novas frentes de exploração econômica e a Igreja Católica com o objetivo de aumentar seu número de fiéis são alguns dos mais visíveis fatores que impulsionaram as práticas coloniais (NEVES, 2009). Para Michel Foucault, dispositivo 
é um determinado agrupamento de práticas, que constituem um sujeito em uma trama de saberes e em um jogo de forças que lhes são imanentes.

Conjunto decididamente heterogêneo que engloba discursos, instituições, organizações arquitetônicas, decisões regulamentares, leis, medidas administrativas, enunciados científicos, proposições filosóficas, morais, filantrópicas. Em suma, o dito e o não dito são os elementos do dispositivo. O dispositivo é a rede que se pode estabelecer entre estes elementos. (FOUCAULT, 2006, p. 244)

Uma das principais dicotomias que se estabeleceu entre colônias e metrópoles, sobretudo na América Latina, ainda hoje bastante presente, são as definições de moderno e anacrônico. Mas, apesar de toda produtividade destas supostas oposições, não é simples definir o que é ser moderno. Esta pergunta certamente rende debates e teses infindáveis, com as mais variadas respostas. Para Bruno Latour (2009, p.15): "A modernidade possui tantos sentidos quantos forem os pensadores ou jornalistas. Ainda assim, todas as definições apontam, de uma forma ou de outra, para a passagem do tempo."

Existe uma batalha entre as definições de "moderno" e "antigo", cuja vitalidade, no entanto, é muito frágil e logo se exaure, pois esta não seja, talvez, um jogo de exclusões, mas sim de choques equilibrados, que não se excluem, mas se misturam, sem se fundirem ou se anularem, uma luta sem fim e sem vencedores. Não adianta tentar buscar o moderno no horizonte do tempo, porque haveria uma grande escala de modernos, um mais velho do que o outro. É possível entender a modernidade como um projeto político de dominação, que inclusive atravessa o tempo e chega ao século XXI bastante fortalecido.

Segundo D. Mignolo (2003, p. 80), o desenho do sistema mundial moderno começa com as grandes navegações ibéricas, "a conexão do Mediterrâneo com o Atlântico através de um novo circuito comercial, no século 16, lança as fundações tanto para a modernidade quanto para a colonialidade". As relações de trabalho, econômicas e sociais desta nova ordem, um "moderno sistema mundial" começam a se desenhar neste momento. Para compreender as perspectivas das sociedades que se forjaram a partir destes processos é necessário

[c]ontar as histórias não apenas a partir do interior do mundo "moderno, mas também a partir de suas fronteiras". Estas não são apenas contra-histórias ou histórias diferentes, são histórias esquecidas que trazem para o primeiro plano, ao mesmo tempo uma nova dimensão epistemológica da, e a partir da margem do sistema mundial colonial/moderno, ou se quiserem, uma epistemologia da diferença colonial que é paralela à epistemologia do mesmo. (D. MIGNOLO, 2003, p.80)

O colonialismo lusitano não se extinguiu com o grito de Dom Pedro I, às margens do Ipiranga. Em 1822, agenciada pelos interesses ingleses, houve, na verdade, a independência de um grupo de portugueses e seus herdeiros, que fundaram o Império do Brasil. A outra colônia lusitana na América do Sul, cuja capital era Belém, a província do Grão Pará, não tinha relações políticas com o Brasil e a partir de uma abordagem bélica, contra a vontade da população local, foi violentamente incorporada ao novo império. Esta adesão fez eclodir uma grande revolta popular, a Cabanagem. 
Não é por acaso que a guerra dos cabanos do Pará e do Amazonas é esquecida pela historiografia. A Cabanagem do Pará é o único movimento político dentro do Brasil em que os pobres tomaram o poder, de fato. É o único e isolado episódio de extrema violência social, quando os oprimidos - a ralé mais baixa, negros, tapuios, mulatos e cafuzos, além de brancos tão rebaixados que parecem não ter direito à branquidade, quase um exponencial de classe - assumem o poder e reinam absolutos. (CHIAVENATO 1984, p.12)

Em relação à Amazônia brasileira, a situação assumiu um caráter ainda mais dramático com a independência do Brasil. As teias do colonialismo na América Latina mudaram para as mãos de uma elite euro-americana, que ganhou vários novos contornos, mas manteve as práticas de colonialidade estabelecidas a princípio pelas metrópoles europeias. O fim da Cabanagem, em Belém teve como resultado uma redistribuição significativa da população da cidade, com a finalidade de evitar novos levantes. Também há de se considerar que uma grande parte dos cabanos ou fugiu para as cidades menores, ou foi assassinada pelo exército brasileiro. Para D. Mignolo (2003, p.129):

\begin{abstract}
A colonialidade do poder deve ser distinguida do período colonial, que se estende na América Latina do início do século 16 ao início do século 19, quando o Brasil e a maioria dos países de língua espanhola conquistam a independência da Espanha e de Portugal e começaram a constituir-se em estados-nações. O colonialismo, como observa Quijano, não se extinguiu com a independência porque a colonialidade do poder e do saber mudou de mãos, por assim dizer, subordinou-se à nova e emergente hegemonia epistemológica: não mais a Renascença, mas o Iluminismo.
\end{abstract}

As Américas são conhecidas ideológica e politicamente como o "novo mundo" e estes continentes, mais do qualquer tecnologia, são a grande "invenção" da modernidade. O moderno, no entanto, não se impõe sem luta e esta luta não é contra o "antigo" ou contra as "tradições", mas sim uma luta pelo poder, uma batalha para desautorizar saberes e eleger outros sob o pretexto de uma lógica, legitimada por instituições e pessoas, uma luta pela subjetivação dos sujeitos, suas práticas e seu próprio corpo.

Este grande dispositivo, o sistema colonial, engloba o poder colonial das metrópoles europeias e a colonialidade, que representa sua atualização, com seus diferentes matizes, prossegue nas histórias das sociedades amazônicas e em muitas outras histórias da América Latina, a moeda colonialidade/modernidade continua a se atualizar e ela está intensamente presente, sobretudo nas ações do poder público na cidade.

\title{
2. A cidade latino-americana: entre línguas e paisagens
}

Em Belém, uma das principais referências da memória arquitetônica da cidade está relacionada às Igrejas Católicas mais antigas e aos edifícios coloniais, casarões, escolas, hospitais, prédios da administração pública. Assim como aconteceu com todas as primeiras cidades brasileiras, foram as paisagens europeias que se impuseram como uma espécie de memória oficial das cidades. Nosso olhar reconhece na arquitetura colonial o familiar histórico. 
Esse conjunto de bens e práticas tradicionais que nos identificam como nação ou como povo é apreciado como um dom, algo que recebemos do passado, com tal prestigio simbólico que não cabe discuti-lo. As únicas operações possíveis - preservá-lo, restaurá-lo, difundi-lo - são a base mais secreta, a simulação social que nos mantêm juntos. (CANCLINI, 2006, p. 160)

Cidades como Salvador, São Luís, Belém, Rio de Janeiro exibem seus centros históricos como algumas de suas paisagens mais significativas e eles constituem uma espécie de verdade única sobre a história da cidade. Os topônimos também revelam o silenciamento da pluralidade étnica das cidades brasileiras. Eventualmente algum político se esforça para criar a Praça do Índio, mas esta denominação costuma, com muita facilidade, ser substituída por um nome mais "civilizado".

Em Belém, a Praça Brasil, como é conhecida pela maioria dos moradores, passou por este processo de apagamento e poucas pessoas a reconhecem como a Praça do Índio. No centro desta praça há um grande índio esculpido em bronze, bastante abandonado, e apesar de seu tamanho, é invisível aos olhos de grande parte dos frequentadores do lugar. A praça recebeu este nome, quando a região ainda não era um bairro de classe média, mas como hoje o que se destaca são as grandes mangueiras e um suntuoso prédio do Tribunal da Justiça do Trabalho, rodeado por diversos escritórios de advocacia e muitos edifícios luxuosos, a denominação oficial não faria muito bem à especulação imobiliária. "Paisagem enquanto forma, a imagem corresponde a uma seleção perceptivo-estética que, de modo espetacular, produz manifestações autoidentitárias da cidade, até transformá-las em seus registros emblemáticos." (FERRARA, 2012, p. 46)

As cidades, as vilas e povoações da Amazônia nasceram, em geral, de antigas aldeias das missões e de fortalezas do período colonial, mas também de "currais de índios" - uma espécie de arraial para abrigo temporário de tropas de descimento e resgates. Na segunda metade do século XVIII, seus habitantes, basicamente índios, tiveram que ajustar-se às novas diretrizes pombalinas para que, nas aldeias transformadas em vilas, as casas fossem construídas com "uniformidade e retinilidade". (BESSA FREIRE, 2004, p.182)

Como aconteceu no litoral sudeste do Brasil, no Pará e no Maranhão viviam muitas sociedades Tupinambá, as primeiras contactadas pelos portugueses. A Igreja Católica, depois da experiência no Rio de Janeiro e na Bahia, já havia elaborado estratégias mais sofisticadas para lidar com estas sociedades indígenas, no início do século XVII. Em Belém, indígenas desta mesma sociedade, foram também perseguidos pelos portugueses, muitos morreram, mas, uma boa parte se rendeu à catequese e se incorporou à população pobre da cidade.

A influência destes povos indígenas, porém, ainda hoje é bastante evidente nas práticas cotidianas dos moradores de Belém. Se não podemos vê-la materializada na arquitetura dominante nos centros históricos, podemos pensá-la, por exemplo, no tradicional almoço paraense que acontece depois da procissão do Círio de Nazaré, com vários pratos regionais, regados ao molho de tucupi, bastante associados à culinária indígena.

No segundo domingo do mês outubro, acontece pelas ruas dos centros históricos, a maior procissão religiosa do Brasil, que costuma reunir mais de dois milhões de romeiros. As milhares de pessoas que acompanham a berlinda da santa e toda a 
movimentação que envolve o antes e o depois da procissão revelam a heterogeneidade da cidade. Apesar de administrada pela Igreja Católica, trata-se de um grande acontecimento, que reúne fieis de várias religiões. Acontecem programações oficiais e paralelas, com direito a uma grande festa GLBT, na véspera da procissão principal.

Se o sistema colonial, com suas igrejas, colégios e hospitais estabeleceu uma ordem de produção de sentidos para a cidade de Belém, nas negociações cotidianas de sentido, as práticas culturais subalternizadas também encontram estratégias de se apropriar deste grande acontecimento que é o Círio. A partir de suas lógicas de consumo e de sociabilidade, produzem novas interpretações para a cidade e seu acontecimento mais emblemático na mídia nacional e internacional.

A cidade de Belém é constituída por dois centros históricos, o primeiro, que se criou em torno do Forte do Castelo, com suas ruas estreitas, apresenta uma influência notadamente portuguesa. Há muitas igrejas antigas, muitos casarões coloniais e esta é a paisagem que se mostra aos olhos de quem chega à cidade pelo rio.

Delineando um segundo centro histórico, mais recente, construído a partir do final do século XIX, sob os efeitos da Belle Époque tardia na região, proporcionada pela extração da borracha, há uma Belém mais afrancesada. Com seus grandes casarões e suas largas avenidas, nesta parte da cidade, existem algumas praças muito semelhantes às étoiles parisienses.

O título de Paris na América $^{2}$, no início do século XIX, tão aclamado pela sociedade da cidade, mostrava como o discurso do colonizador havia se estabelecido. Era necessário chegar a um nível superior dentro da tradição ocidental e as cidades portuguesas, no final do século XIX, não representavam modelo de metrópole. Muitos anos depois da Independência, a cidade elege Paris como modelo de urbanidade, mais luzes e menos igrejas.

Hoje, Belém se constitui com seus centros históricos e incontestavelmente eles fazem parte da identidade da cidade. Existe, no entanto, um lugar em que há um escape da arquitetura colonial, trata-se da maior feira ao ar livre da região, o Ver-o-Peso. Lá já foi palco da Cabanagem. Vários governos tentaram mudar sua dinâmica. Em muitos momentos as políticas públicas deixaram a feira, literalmente, abandonada. No meio do complexo arquitetônico do Ver-o-Peso, foram erguidos o Mercado de Ferro e o Mercado de Carne, feitos com estruturas de ferro totalmente importadas da Europa. É neste espaço que a população mais pobre da cidade, há muitos séculos, também desenha sua memória.

O Ver-o-Peso é, antes de tudo, o movimento dos barquinhos, trazendo verduras, frutas, peixes e todo o colorido, pintando em suas barracas uma grande aquarela amazônica, que deixa ver a forte memória indígena viva no cotidiano de Belém. (NEVES, 2009, p. 91)

Essas águas, que contornam o Ver-o-Peso são algumas das principais ruas da região e dão conta de uma memória mais antiga que a colonial. Hoje, esta grande feira ao ar livre é o principal cartão postal da cidade e figura entre as dez maravilhas arquitetônicas do Brasil. Podemos, então, pensar que por mais mediativo que seja o poder de estabelecer uma memória oficial, ele pode não apagar a força da imaginação de seus moradores e nem impedir a produção de identificações não-oficiais. "Nesse sentido, a paisagem da cidade é, sobretudo, de natureza comunicativa e interativa

\footnotetext{
${ }^{2}$ No final do século XIX, por importar um modelo cultural parisiense, que estava presente nas roupas, na arquitetura, nas produções artísticas, coube à cidade de Belém o título de Paris na América.
} 
porque, se não se faz sem registros, também não dispensa vínculos afetivos". (FERRARA, 2012, p.46)

As experiências vividas por séculos entre os feirantes e os moradores da cidade é algo que escapa, que desestrutura um discurso patrimonialista de conservação. Suas paredes não são de mármore, seus feirantes não pertencem às classes dominantes, os barquinhos que por lá trafegam são de pessoas do povo e muitos deles devem ser descendentes daqueles Tupinambá que foram incorporados à população das cidades.

Nossa ideia de cultura projeta uma paisagem antropológica povoada de estátuas de mármore, não de murta $^{3}$ [...] Talvez, porém, para sociedades cujo (in)fundamento é a relação aos outros, não a coincidência consigo mesmas, nada disso faça o menor sentido. (VIVEIRO DE CASTRO, 2007, p. 195).

400 anos depois, com aproximadamente 2.200.000 habitantes, a área metropolitana continua em franco processo de pluralização histórica e cultural. Situada em uma península, no final do século XX, o crescimento da cidade alcançou os municípios vizinhos de Ananindeua, Marituba, Benevides e Santa Izabel. Novas e antigas memórias se tencionam nas paisagens da cidade.

Na imagem a seguir, uma fotografia de Belém tirada na Baía do Guajará, mostra a grade parede tabulada por prédios muito altos, autênticos representantes da contemporaneidade da cidade. Estas construções são responsáveis pelo maior aquecimento da cidade nos últimos anos e representam um grande obstáculo à circulação dos ventos oriundos da baía do Guajará e do rio Guamá, que contornam a cidade.

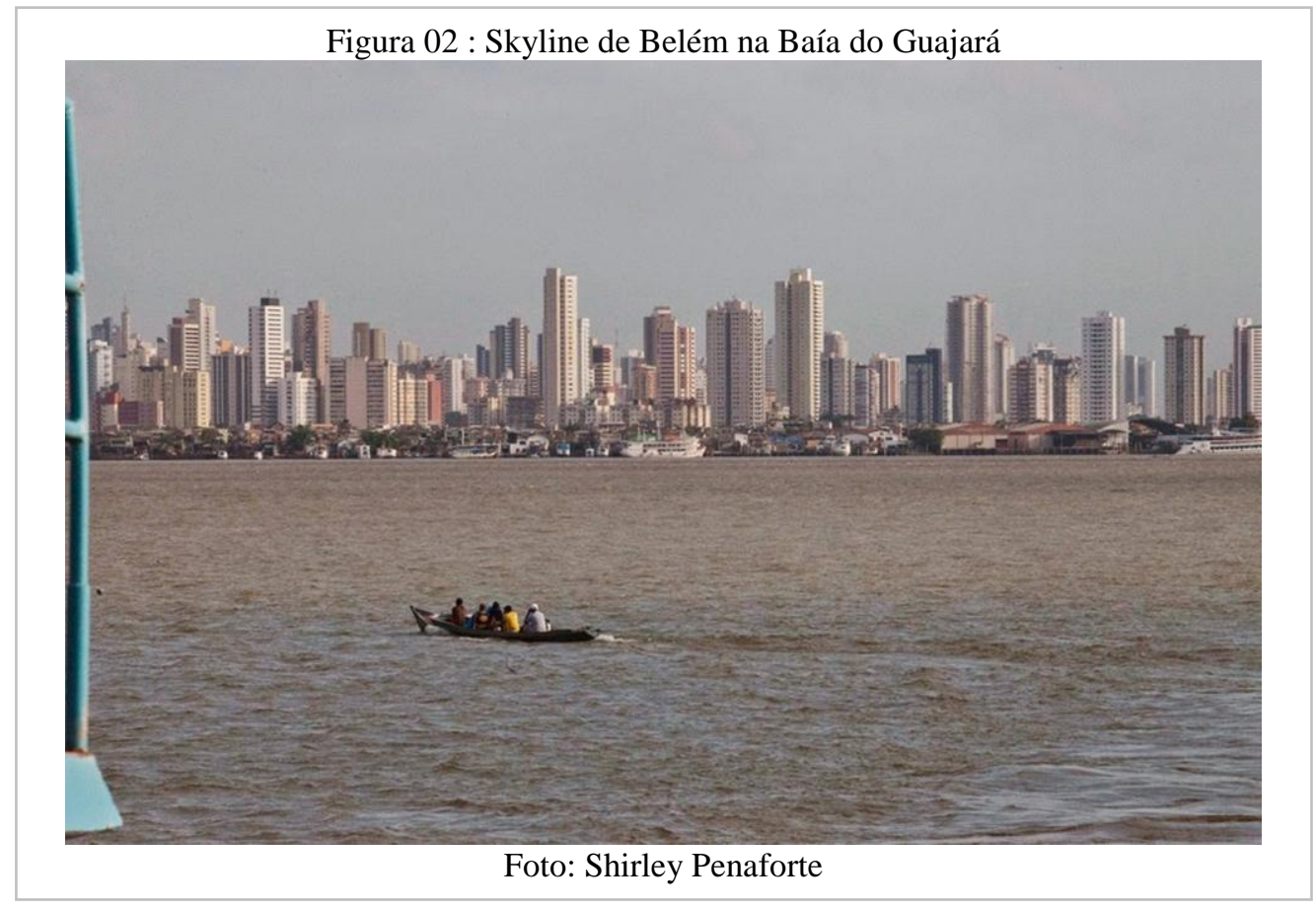

\footnotetext{
${ }^{3} \mathrm{Na}$ região norte, murta é mais conhecida como palha.
} 
O processo de verticalização de Belém se intensificou em três bairros de classe média e a paisagem dos grandes edifícios se superpõe à arquitetura colonial. A cidade também deseja o poder conferido pela altura de suas construções.

O skyline da cidade é um gráfico que registra as flutuações de seu poder econômico, mas, sobretudo, assinala o valor simbólico da altura como comunicação de uma cidade com o mundo. Para a cidade, a altura é uma mídia, um índice capaz de fazer com que sejam comunicados seus pontos de referência e o poder que, a exemplo das pirâmides do Egito, poderá identificá-la na história. (FERRARA, 2008, p. 40)

Este novo ecossistema altera profundamente a relação dos moradores da cidade com o rio, uma das principais heranças indígenas, pois o acesso principal, agora privatizado, acontece pelas janelas dos andares mais altos. A maior parte dos moradores vive em bairros periféricos, com infraestrutura precária, invisibilizados pelas políticas públicas. As últimas administrações municipais não fizeram um planejamento urbano com alternativas de transporte e a cidade agoniza. As campanhas institucionais da prefeitura contrastam com a realidade observável.

\section{O aniversário como acontecimento discursivo}

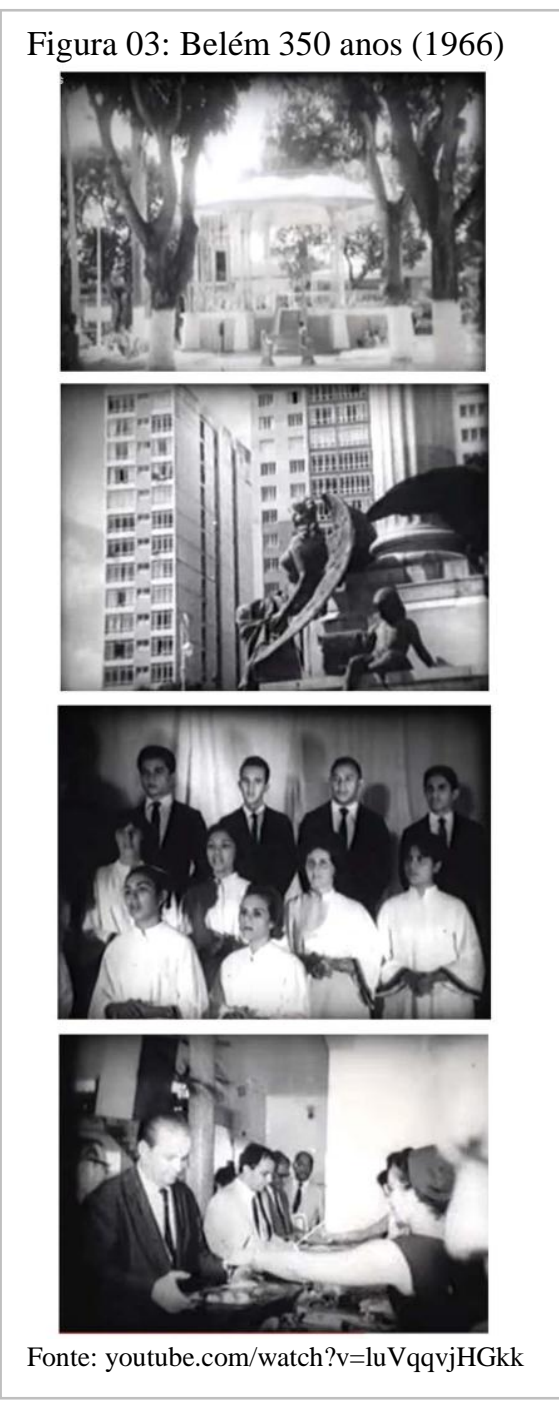

Na Europa, nós não temos datas de fundação das cidades. Eu não sei quando foi fundada a cidade de Lisboa. Sabemos as datas de fundação de uma ou outra instituição mais antiga. Comemorar o aniversário das cidades é uma particularidade de vocês.

Adriano Rodrigues

Em 1966, por ocasião das comemorações dos 350 anos de Belém, também houve uma intensa movimentação midiática. Os principais jornais impressos visibilizaram a cidade moderna, a arquitetura colonial, a população vestida de forma civilizada. Por iniciativa do Governo do Estado, uma das mais famosas cantoras do rádio, Dalva de Oliveira, gravou a música "Parabéns, Belém", de Afonso Monteiro e Pires Cavalcante, em homenagem ao aniversário. A produção cinematográfica ficou sob a responsabilidade de Líbero Luxardo, que em conjunto com a Universidade Federal do Pará produziu o filme "Belém 350 anos" (1966).

As imagens ao lado também visibilizam a arquitetura de inspiração francesa e a cidade moderna. Há um destaque para os grandes edifícios, que silenciam a existências de grandes bolsões de misérias. São os anos iniciais da última ditadura militar (1964/1985) e os discursos sobre a integração da Amazônia, iniciado no começo do século XX, serão bastante reforçados pelos militares e a urbanidade desta Belém, exibida nas mídias, reafirmava a necessidade de "civilizar a Amazônia". 
A população da cidade, ainda que em desacordo com o clima da região, como acontece também nos registros visuais do início do século $\mathrm{XX}$, aparece vestida com roupas de pessoas "cultas e modernas". Não há, nestes registros, qualquer vestígio da presença indígena ou africana na cidade, ou ainda qualquer indicação dos graves problemas de infraestrutura que afetavam a maior parte dos moradores da cidade.

É certo que estes registros não traduzem todas as vozes dissonantes que enunciaram o aniversário de 350 anos de Belém. É bem provável que nas emissoras de rádio, a mídia mais popular da cidade naquele momento, houvesse programas de denúncia em relação à infraestrutura precária da cidade. Também é bem possível que em grande parte das conversas cotidianas sobre a comemoração, esta cidade fictícia fosse bastante questionada. Estas diferentes posições, no entanto, embora tenham sido silenciadas nos registros oficiais, não se dissolveram e continuaram presentes nas memórias submersas sobre a pluralidade étnica da cidade, bastante presente no cotidiano dos moradores.

Entre 1966 e 2016, as "novas" tecnologias da informação transformaram significativamente o panorama global da comunicação e Belém, com suas contradições, insere-se neste novo espaço de produção de sentido nas redes sociais. As "novas" tecnologias, sobretudo as da informação, hoje, representam neste jogo político estabelecido pelo sistema colonial, uma espécie de última fronteira da modernidade, um termo/conceito flutuante e progressivo. Os movimentos da história das tecnologias não são estáticos e nem começaram com o telefone celular ou com a internet, embora não se possa ignorar que nas últimas décadas, a velocidade das transformações acelerou e junto com ela, uma política de sentidos que envolve a produção e o acesso a estas tecnologias.

Os aparatos tecnológicos podem se transformar, se atualizar ou desaparecer, mas não ficam inflexíveis às transformações das práticas culturais. Isso é quase uma máxima em se tratando de tecnologia. Com a expressão novas tecnologias, definem-se, no momento atual, as tecnologias da informação e da comunicação, compostas por um conjunto de discursos, que estão inseridos em diversos campos, facilitados pelos computadores, sistemas de interação de computador e usuário, digitalização da informação, comunicações via satélite, telefonia e redes de comunicação, além do desenvolvimento dos meios audiovisuais, com os quais os computadores e sujeitos interagem. Elas se apoiam na tecnologia digital e na tecnologia tradicional por meio dos bits, bytes e átomos, mediante os quais se processam, se acumulam e se transmitem as informações.

A nova sociedade globalizada se constitui em um momento que nem é novo e nem antigo, pois tudo acontece ao mesmo tempo. O tradicional e o contemporâneo convergem para processos de recepção e aqueles que possuem mais acesso a estes meios, tem maiores possibilidades de sucesso no campo comunicacional. Neste cenário, no entanto, nem todos estão conectados a estas redes, este acesso também não é homogêneo e se diferencia de um território para outro. (JENKINS, 2009)

As tecnologias da informação e comunicação, com suas mídias digitais e a internet assumiram grande importância dentro do funcionamento das empresas, representam um dos principais meios de divulgação do conhecimento e servem como meio de relacionamento, contribuindo para construção de uma nova identidade, a virtual. As pessoas que tem acesso à internet passaram a incorporar em suas práticas sociais esta multiplicidade de serviços ofertados pela evolução tecnológica. Neste novo momento, gerado pelo desenvolvimento da rede de computadores, é necessário estar em constante aprendizado, haja vista que as linguagens e o conhecimento tecnológico se tornam rapidamente ultrapassados. 
$\mathrm{Na}$ Amazônia, a internet continua se estabelecendo a partir de diferentes acontecimentos, e, em muitos lugares, ela não faz sentido, ainda não permeia as práticas culturais dos moradores. Na geopolítica da região, há lugares que ainda não contam com rede de energia elétrica, mas mesmo assim, isso não impede das pessoas encontrarem novas formas de ter acesso à informação, quer seja pelo rádio, adquirindo pequenos geradores e antenas parabólicas, ou ainda visitando cidades com acesso à internet. E neste sentido, como afirma George Yúdice (2004, p. 28): “A globalização pluralizou o contato entre diversos povos e facilitou as migrações, problematizando assim o uso da cultura como expediente nacional".

Em Belém, a segunda maior cidade da região norte, a chegada dos smartphones e da internet e os seus usos sociais vem modificando a maneira como as pessoas estabelecem as interações dentro e fora da região onde vivem. Alteram-se as formas cotidianas de relacionamento, e de maneira geral, há uma "ruptura" com as práticas antecedentes, que passam a se dinamizar. Neste contexto, os meios massivos tradicionais reconfiguram suas lógicas e nada voltará a ser como antes. Certamente que 1966, se os moradores da cidade tivessem acesso a estas tecnologias, hoje haveria uma versão mais plural deste aniversário da cidade.

Para compreender este aniversário como um acontecimento discursivo e o processo de visibilidade e apagamento da presença indígena, é preciso situá-lo como um nó numa rede de memória e considerar tanto os aniversários anteriores e os que ainda estão por vir, como 450 ou 500 anos, por exemplo. A exemplo do que ocorreu em 1966 e pode acontecer em 2066, em 2016, anos antes de sua realização, ele começou a se organizar em vários pequenos acontecimentos. É possível assinalar nesta rede de memórias e acontecimentos algumas regularidades e muitas dispersões. Para Foucault (2005, p.28):

É preciso estar pronto para acolher cada momento do discurso em sua irrupção de acontecimentos, nessa pontualidade em que aparece e nessa dispersão temporal que lhe permite ser repetido, sabido, esquecido, transformado, apagado, até nos menores traços, escondido bem longe de todos os olhares, na poeira dos livros.

Assim como acontece no mundo todo, a fundação ou a comemoração de aniversário estarão bastante relacionadas aos processos históricos e culturais que constituem as cidades. $\mathrm{O}$ aniversário de fundação, necessariamente, não representa um grande acontecimento discursivo e nem nossas teorias, nem a mídia são seguramente capazes de produzi-lo. As comemorações, ainda que estejam envolvidas em grandes produções midiáticas, podem não afetar a população local. No projeto de pesquisa "Belo Horizonte 100 anos depois: as novas condições da experiência", os resultados mostraram que a campanha midiática da prefeitura não obteve os desdobramentos esperados, entre os moradores.

O aniversário ganha corpo na medida em que ele é pronunciado por alguém e se torna construção subjetiva. Podemos dizer que ele é fruto de um "contar": um "contar" o tempo, a partir do estabelecimento de marcações, mas também um "contar" aos outros, anunciar, partilhar um sentido, uma informação. Dessa maneira, constitui-se em produção discursiva - é produzido pela palavra e pela comunicação entre homens. (SILVA; FRANÇA, 1998, p. 429)

Nas campanhas das eleições municipais de 2012, a preocupação já estava presente, afinal, o prefeito eleito seria o enunciador mais autorizado deste espetáculo 
midiático. Em outubro de 2014, notadamente durante a programação do Círio de Nazaré, pudemos acompanhar, pela televisão e pelas redes sociais, o início de ações mais sistemáticas da prefeitura, com a apresentação do slogan "Rumo a Belém 400 anos". Outras instâncias governamentais e privadas, assim como iniciativas de coletivos, artistas e pesquisadores também começaram a ganhar visibilidade.

\section{Belém 400 anos: a cidade luz e outros lados}

A mediação estabelecida pelas imagens ocupa um significativo papel no processo de subalternalização dos povos indígenas no Brasil, que continua a atualizar o sistema colonial. Os desenhos, as pinturas, as fotografias e mais recentemente as imagens em movimento foram e continuam sendo muito significativas nos processos de interação com as sociedades latino-americanas. Agora, nas redes sociais, ou mesmo nas luxuosas impressões de livros e revistas, ou ainda nos muros das cidades, estas imagens atualizam memórias, refutam e reforçam discursos sobre estas sociedades. $\mathrm{O}$ apagamento dos indígenas em quase todas as imagens mostradas, à exceção do muro na entrada de Belém, nega a pluralidade étnica da região.

A imagem é um operador de memória social, comportando no seu interior um programa de leitura, um percurso inscrito discursivamente em outro lugar. Esse programa de leitura está inscrito na própria materialidade da imagem, mas é um percurso que, lógico, não nasce na imagem, há todo um processo de intertextualidade, de interdiscursividade, da memória das imagens que vão produzir isso que é um acontecimento, mas que não prescinde, de maneira nenhuma, da história. (GREGOLIN, 2011, p 93).

Os mais de dois milhões de moradores da área metropolitana, pelo menos desde 2012, interagem com uma produção midiática local, que se intensifica, à medida que se aproxima o aniversário. Gradativamente, são colocados em circulação discursos das mais diversas ordens sobre a cidade.

\subsection{A cidade luz, rede de memória e silenciamento}

No aniversário de 399 anos, a Prefeitura colocou à disposição da população o painel a seguir, que foi pensado para homenagear a fundação da cidade. Há um espaço para as pessoas colocarem o rosto e fazer um registro fotográfico. Uma série de fotografias em que o público interage com o painel está disponível na página da Prefeitura de Belém, no Facebook. A cidade moderna e civilizada do filme "Belém 350 anos", de Líbero Luxardo, dialoga bastante com o discurso deste painel.

As roupas, os adereços, os gestos, os corpos desenhados não deixam qualquer dúvida sobre a origem europeia dos fundadores da cidade e há um claro apagamento da pluralidade étnica. Não existem referências à invasão militar da região promovida por Francisco caldeira Castelo Branco e seus soldados em 1612. A imagem faz uma homenagem ao segundo nascimento europeu da cidade, o final do século XIX, quando Belém ganhava cores parisienses. 


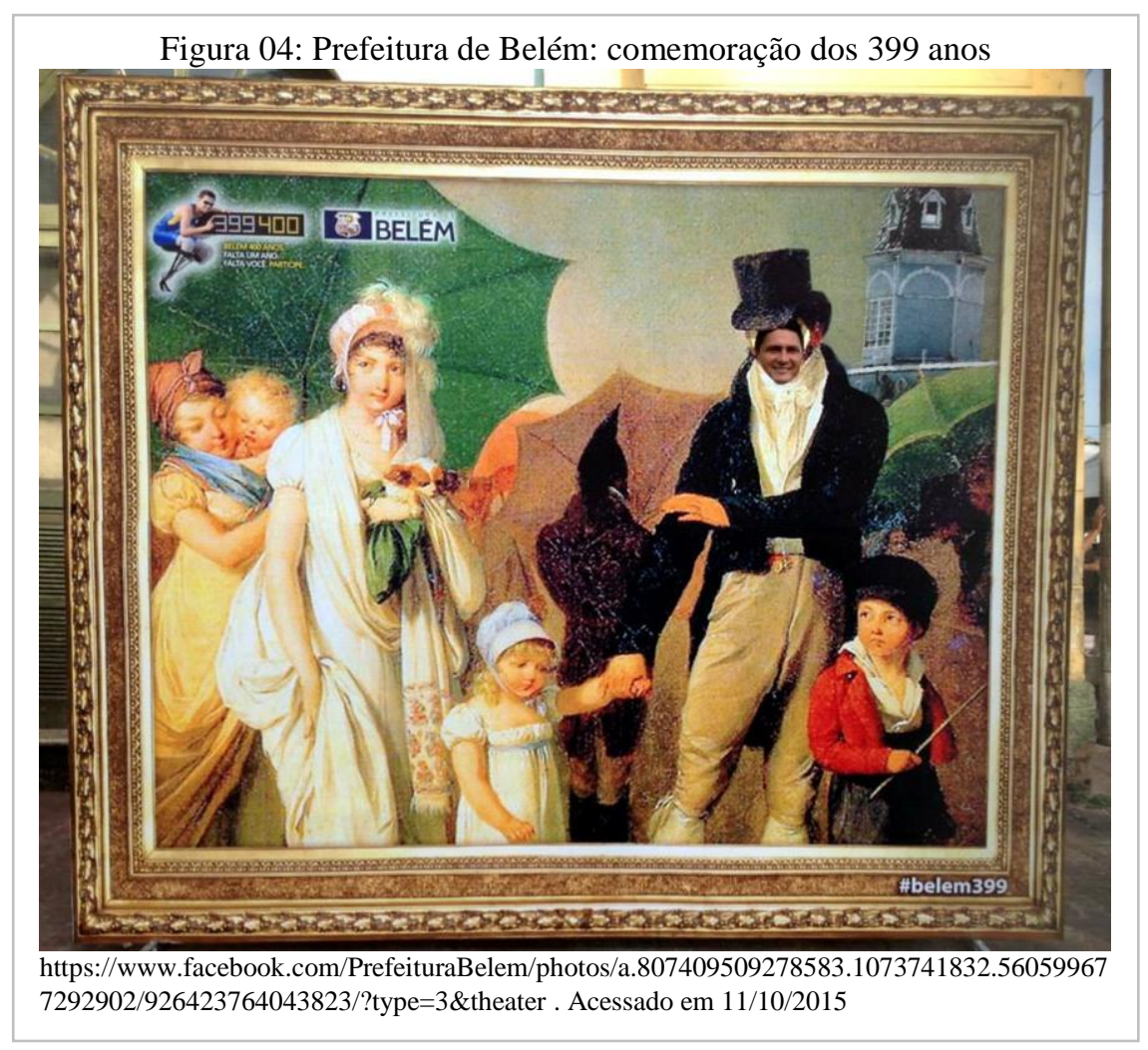

A memória eurocêntrica está bastante associada com a proposta do vídeo disponibilizado no Youtube, que também circula na TV Liberal, afiliada local da Rede Globo e em todas as plataformas desta corporação, "Belém, Cidade Luz da Amazônia". A próxima figura mostra a abertura do vídeo e deixa ver a convergência midiática de sua circulação.

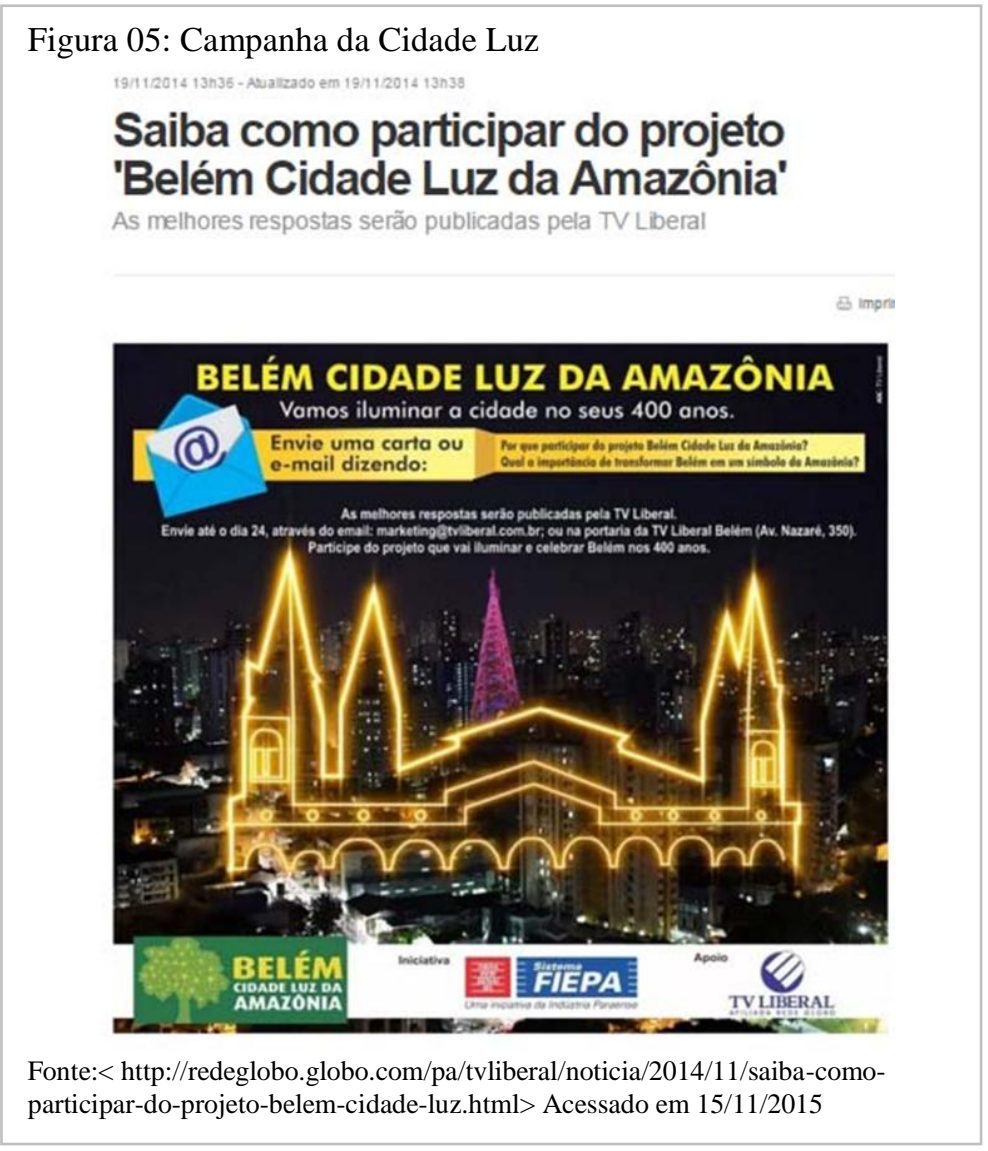


A análise destes dois enunciados revela que os discursos colocados em circulação pelas campanhas institucionais são bem semelhantes aos dos grandes grupos de comunicação e esta posição encontra muitos adeptos na sociedade local. A descendência europeia aparece como uma verdade única na fala de muitos pesquisadores, de jornalistas, de professores e de uma parte considerável da classe média da cidade. Para estas pessoas, práticas culturais de matrizes indígenas ou africanas devem ser banidas da civilidade de Belém. Neste momento da história, as lideranças locais assumem o discurso da modernidade/colonialidade, pois elegem uma cultura superior como modelo de civilidade, vinculada às ideias do iluminismo francês. Este é um processo bastante recorrente na América Latina, como bem assinala D. Mignolo (2002).

\subsection{De outros lados}

Nas redes sociais, há uma grande movimentação em relação aos 400 anos da cidade. Coletivos, grupos de jornalistas, pesquisadores, políticos de oposição, profissionais liberais, entre outros sujeitos, estão se apropriando deste espaço para postar suas posições sobre o aniversário. De forma geral, há uma crítica à infraestrutura precária dos bairros periféricos da cidade e às atitudes do prefeito na condução da festa de comemoração do quarto centenário. Um dos resultados mais notórios desta movimentação foi a escolha, através de uma votação nas redes sociais, de um novo logotipo para simbolizar os 400 anos.

Em relação à pluralidade étnica de Belém, não há uma grande quantidade de postagens, até novembro de 2015. Nem mesmo os movimentos negros, bastante atuantes na cidade, ainda não intensificaram esta discussão nas redes sócias. Quanto à presença indígena, não é muito diferente, mas duas páginas do Facebook fazem referências bem pertinentes à memória destes povos: Outros 400 e Gueto 400.

A página Outros 400 faz parte do Portal Outros 400, criado por um grupo de jovens jornalistas e publicitários, com o objetivo de divulgar as atividades do quarto centenário de Belém e a agenda cultural de eventos, além de se propor a discutir os problemas e o futuro da cidade. A logomarca deste portal é um urubu, um grande pássaro negro bastante associado à feira do Ver-o-Peso, que também originou o nome de uma das páginas do portal, Urubuservando. A postagem a seguir é parte da campanha de lançamento do portal:

O aniversário de 400 anos de Belém se aproxima e certamente você já leu, ouviu ou assistiu a alguma exaltação à história da cidade. Francisco Caldeira Castelo Branco, conquistador e fundador de Belém! Ah, a Belle Époque, que linda! E no tempo do Barata? Naquele tempo é que era bom, não era? Histórias que narram uma parte da história da cidade: a história dos "vencedores", dos que compuseram a elite da capital paraense no decorrer desses 399 anos.

$\mathrm{E}$ os indígenas Tupinambá que resistiram até o fim à colonização portuguesa? E quanto à higienização e elitismo da Belle Époque? E os escravos indígenas? E a escravidão africana? (...)

Hoje o urubu começa sua jornada. Longe do maniqueísmo entre opressores e oprimidos, contará a história de Belém sob seu ponto de vista. A história é mais complexa. Ele viu a fundação de um forte que, no futuro, se tornou a cidade. Ele vê como cada decreto municipal impacta seu reino de trabalhadoras e trabalhadores todos os dias em Belém. O passado, o presente e o futuro de Belém: só urubuservando! 
Esta outra posição reivindica uma memória indígena de Belém, inclusive assinala que já havia moradores na região, quando os portugueses começaram a ocupação. Esta informação, ainda que possa parecer óbvia, desaparece nos discursos que homenageiam o colonizador. Outro aspecto destacado, a escravidão de indígenas e negros, bastante associada à criação da periferia de Belém, também é muito relevante neste momento. Fundamentalmente, este enunciado destaca o conflito étnico da fundação que boa parte da sociedade local faz questão de apagar.

A próxima postagem, também do Portal Outros 400, é uma entrevista com o dos criadores da página de Facebook Gueto 400, Francisco Batista e tem por objetivo discutir a programação oficial das comemorações divulgadas pela Prefeitura, no segundo semestre de 2015.

\footnotetext{
Figura 06: Outros 400 e O olhar do Gueto

Não só os bairros mais afastados do centro foram esquecidos na programação. Além da porção continental, Belém é formada por 39 ilhas, que correspondem a $65 \%$ de todo o território do município. Mesmo assim, apenas Mosqueiro, Outeiro e Cotijuba figuram na agenda da festividade. Para as outras 36, restou um "passeio fluvial envolvendo a população das ilhas, as embarcações tradicionais do Ver-oPeso, Marinha do Brasil, barcos privados e soluções de mobilidade fluvial em homenagem aos nossos rios e sua importância nos 400 anos de história de Belém", conforme consta na programação oficial.
}

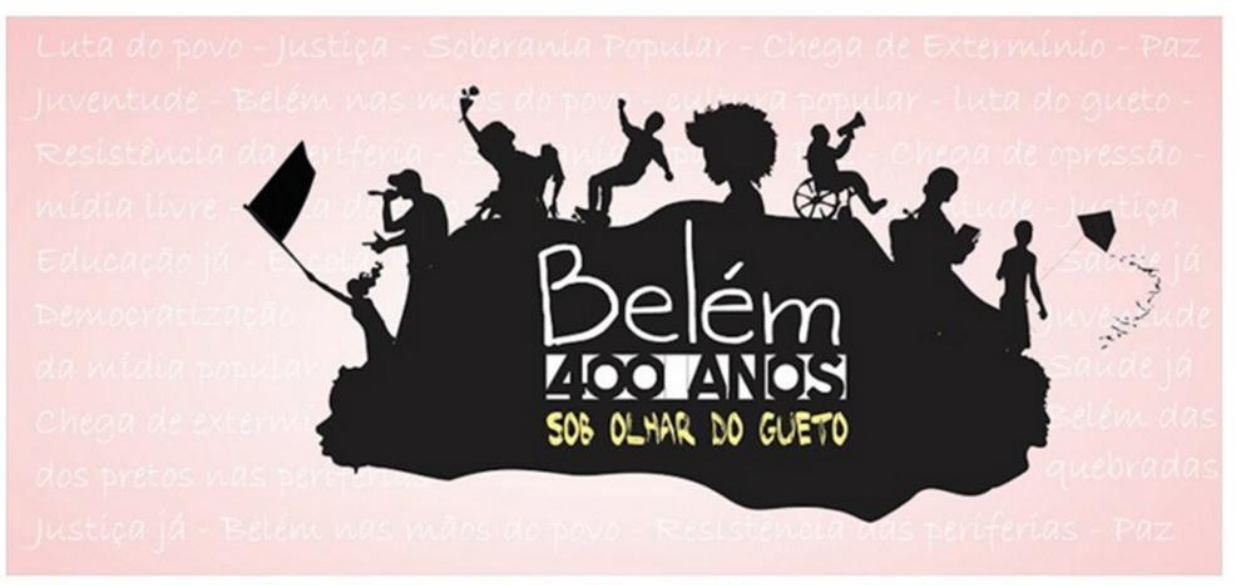

O Movimento Gueto 400 pretende marcar a data dos 400 anos de Belém pautando as demandas e manifestações culturais das periferias da cidade.

"Existe toda uma população ribeirinha que sempre foi esquecida. Se o rio é tão importante para Belém, por que a cidade deu as costas a ele? Por que os ribeirinhos são ignorados?", questiona Francisco. "O Gueto 400 vai elaborar uma carta para o povo de Belém, mostrando nossa agenda de reivindicações, nossa visão de apropriação da cidade, para mostrar que a periferia existe", completa. "A prefeitura quer é fazer festa pra elite, as suas ações são todas só pra isso".

Fonte: http://outros400.com.br/urubuservando/3688

A página Gueto 400 foi criada a partir da integração de movimentos políticos e culturais de diversos subúrbios, que contestam a atuação da Prefeitura. Em linhas gerais, eles desejam um reordenamento das políticas públicas na cidade. Uma das primeiras iniciativas deste grupo foi a realização, em parceria com a Faculdade de Comunicação da Universidade Federal do Pará, de uma série de oficinas voltadas ao jornalismo cidadão. Para fazer frente aos grandes grupos de comunicação, era necessário, primeiro, capacitar estes sujeitos. Existia, já, uma militância destes movimentos da periferia, anterior às discussões sobre os 400 anos, que contestam uma história singular da cidade e o comprometimento dos grandes grupos de comunicação com a desigualdade social. A 
logomarca do grupo procurou contemplar as mais diferentes etnias dos moradores da cidade.

A posição do portal, onde a entrevista foi veiculada, e do Gueto 400 abordam a exclusão da população ribeirinha da cidade, espalhada em 39 ilhas. Destaquei esta reportagem, sobretudo por causa do enunciado "ribeirinha", profundamente imbricado com a memória indígena da cidade. Esta denominação, de certa forma, apaga a descendência indígena e africana da sociedade local. Quem afinal são estes sujeitos que vivem às margens dos rios? Eles já estavam lá em 1616? Estariam eles associados etnicamente aos discursos eurocêntricos?

Não resta dúvida, no entanto, que os moradores da periferia, espalhados pelos subúrbios e pelas 39 ilhas, de alguma forma, estão profundamente envolvidos com a memória dos povos indígenas chacinados pelos primeiros portugueses e seus herdeiros, ou ainda aos que foram incorporados, junto com os afrodescendentes e mais tarde com grandes levas de migrantes nordestinos, à população pobre da cidade. Todos estes grupos não estão comtemplados nas comemorações dos 400 anos e, em geral, são invizibilizados pelos grandes grupos de comunicação, neste momento histórico.

\subsection{Misturando os lados}

A história, no entanto, no sentido que lhe atribui Foucault (2005) é descontínua. Isso significa que estes discursos sobre a pluralidade étnica da cidade de Belém são nós em uma rede de memória, que se move. No momento atual, as lideranças políticas locais retomam o discurso da modernidade/colonialidade, mas nos anos de 1980, um governador chegou ao poder defendendo os ideais da Cabanagem, assim também como já houve um prefeito que se dispôs a realizar dois mandatos consecutivos embalados com os ideais cabanos.

A história se move e os discursos se constituem com momentos de visibilidade e de apagamento. A colonização portuguesa e a Belle Époque, embalada pelos altos lucros do comércio da borracha, marca profundamente a memória de uma parte dos moradores de Belém e se traduzem em seu cotidiano. Sem dúvida, a resistência dos Tupinambá à colonização, a grande resistência da Cabanagem e tantos outros micro acontecimentos, com suas regularidades e suas profundas dispersões, também se inscrevem na memória dos moradores. E não é possível acreditar que este sujeito morador da cidade, hoje, não se constitui, mesmo em graus diferentes, com estas duas posições, numa condição de sentir-se entre elas, ou ainda conceber este processo de forma neutra e pacífica.

\section{Considerações Finais}

O estabelecimento da web tem relação com o processo de convergência cultural pelo qual passa a sociedade contemporânea: a apropriação da internet e de outras interfaces, nas cidades, nas terras indígenas, nos assentamentos e nos mais diferentes espaços amazônicos, não é apenas reflexo de sua popularização, mas se trata de uma modificação na interação que os sujeitos estabelecem com as mídias. $\mathrm{O}$ aniversário de 400 anos de fundação de Belém se delineia como um grande acontecimento discursivo para a sociedade local. Provavelmente, ele não se tornará notícia nacional, o que só acontece com os aniversários das cidades do Rio de Janeiro e São Paulo, mas, com as redes sociais, as comemorações do aniversário de Belém ampliou bastante as possibilidades de interlocução. 
Nos muros e nas paredes espalhadas e espelhadas pela cidade, enunciadores e enunciados inconclusos constituem também uma Belém cosmopolita, assim, como a cidade enunciada nas redes sociais e interage num espaço transnacional, por isso já não podemos pensar em interlocutores que sejam apenas moradores, visitantes ou pesquisadores. Nas postagens da web, Belém se comunica com o planeta.

Neste grande universo de discursos, que muitas vezes se tencionam, há também uma série de sujeitos que reivindicam uma relação mais singular com a cidade, sem assumir a cidade luz e sem se colocar numa posição de contestação. São pessoas interessadas em marcar um lugar para as suas origens, numa das grandes metrópoles da Amazônia. Então chegamos a outro nó discursivo em relação às possíveis identidades de uma cidade: o cosmopolitismo. Segundo Gilberto Velho (2010, p. 20):

As pessoas têm uma experiência complexa, movem-se em múltiplos planos, articulam-se a redes diversificadas e suas identidades não são homogêneas nem se desenvolvem de modo unilinear. Assim, poderíamos dizer que não há cosmopolitas "puros", e o lado doméstico, local, provinciano, autorreferido, endogâmico, reaparece ou está sempre presente em contextos e situações específicos. A aldeia dos ancestrais, o antigo bairro de origem, a casa paterna e suas memórias são exemplos conhecidos e frequentemente se constituem em importantes âncoras identitárias.

Belém, hoje, desenha e redesenha suas paisagens e de forma geral é possível imaginar que seus moradores estabelecem um intenso vínculo de pertencimento à cidade. Os 400 anos estão produzindo sentidos fortemente administrados pela mídia, mas também se significam como uma experiência de mediação entre os belenenses.

Para finalizar, retomo os enunciados com que iniciei este artigo e entendo a condição de sua enunciação fraturada, este "estar entre" latino-americano de que fala D. Mignolo (2002): um enunciado em língua portuguesa, um grafismo indígena e a quase indecifrável sigla de um coletivo de pichadores. Fiz esta seleção, porque considero que a memória indígena desta grande metrópole deve ser entendida a partir desta perspectiva.

O discurso se materializa nos corpos, nas telas, na arquitetura, na comida. Ele vai muito além da palavra falada. Os dispositivos que instituíram o sistema colonial foram bastante rigorosos e estiveram presentes nas mais diferentes materialidades. Por outro lado, por mais violentos e rigorosos que tenham sido, sempre houve quem resistisse a eles. O olhar como gesto interpretativo estabilizou discursos, mas é também a partir do seu deslocamento que podemos, talvez, quem sabe, escrever e visibilizar outras histórias, que estejam além das línguas e da arquitetura europeias e dos grandes edifícios, feitas também com palha, grafismos indígenas, siglas de coletivos de pichadores e bytes.

\section{Referências}

BESSA FREIRA, J.R. Rio Babel: a história das línguas na Amazônia. Rio de Janeiro: EDURJ, 2004.

CANCLINI, Nestor Garcia. Culturas Híbridas. São Paulo: Edusp, 2006.

CHIAVENATO, Júlio José. 1984. Cabanagem: o povo no poder. Ed. Brasiliense, São Paulo. 
FERRARA, Lucrécia. As mediações da paisagem. Revista Líbero, São Paulo, v. 15, n. 29, p. 43-50, 2012.

Cidade: meio, mídia e mediação. Revista Matrizes, n. 2, 2008.

FRANÇA, V. O acontecimento e a mídia. Galáxia (São Paulo, Online), n. 24, p. 1021, dez. 2012a.

O acontecimento para além do acontecimento: uma ferramenta heurística. In: FRANÇA, V \& OLIVEIRA, L. (orgs). Acontecimentos: reverberações. Belo Horizonte, MG: Autentica 2012b, p 39 - 51.

FOUCAUlT, Michel. Microfísica do Poder. Rio de Janeiro: Edições Graal, 1979.

2005.

A arqueologia do Saber. Rio de Janeiro: Forense Universitária,

A ordem do discurso. São Paulo: Edições Loyola, 2000.

GREGOLIN, M. R Análise do discurso e semiologia: enfrentando Discursividades Contemporâneas. In: PIOVEZANI, C. etalli (org.). Discurso, semiologia e história. São Carlos, SP: Claraluz, 2011.

JENKINS, Henry. Cultura da convergência. $2^{\mathrm{a}}$ edição. $2^{\mathrm{a}}$ Reimpressão. São Paulo: Aleph, 2012.

MIGNOLO, Walter. Histórias Locais / Projetos Globais: Colonialidade, Saberes Subalternos e Pensamento Liminar. Belo Horizonte: Editora UFMG, 2003.

NEVES, Ivânia. A Invenção do Índio e as Narrativas Orais Tupi. Tese de Doutorado. Campinas: Unicamp, 2009.

RAMA, Angel. A cidade das letras. São Paulo: Brasiliense, 1985

SILVA, Regina e FRANÇA, Vera. Belo Horizonte fez 100 anos. Revista Projeto História, n. 17, 1998.

VELHO, Gilberto. Metrópole, Cosmopolitismo e Mediação. Revista Horizontes Antropológicos, ano 16, n. 33, p. 15-23, 2010.

VIVEIROS DE CASTRO, Eduardo. Perspectivismo e Multinaturalismo na América Indígena In A Inconstância da Alma Selvagem e outros ensaios de Antropologia. São Paulo: Cosac Naify, 2002.

YÚDICE, George. A Conveniência da Cultura: usos da cultura na era global. Belo Horizonte: UFMG, 2004. 